popularity stems from increased competition over resources and rights, where protests seem to be not only vital tools for concretizing grievances but also a means of creating temporary, yet tangible, communities in cities.

Indeed, competition and contestation are not foreign to me. Living in the Middle East, in Israel-a conflicted zone, where the concept of space is both dynamic and contested-makes me constantly reflect on the fragility and temporality of power, beliefs, and territories. This habitus not only piqued my curiosity but also created some limits in terms of exploring this topic and, in that sense, relating to protests in different parts of the world; the book's perspective is predominantly Western. Thus, I would like to see this exploration as the beginning of a wider discussion on the dynamics between protests and physical spaces.

\title{
ORGANIZATION OF THE BOOK
}

The book has three parts: "Planning Protests," "Spatial Choreographies," and "Continuum." Part I, "Planning Protests," is about the ways in which protesters envision their actions and plan them. In strategizing about how best to act in a particular context, many parameters should be considered. Thus, part I is a broad inquiry into the design of protests in public spaces. It is abstract in its approach, with each of its chapters suggesting general categorization of a particular dimension of the protest-planning process. The discussion is incremental, and the ideas presented in this part should be viewed as building upon one another.

Chapter 1, "Challenging Distance," introduces the book's key premises and the lens through which protests are explored. Chapter 2, "Choosing a Place," focuses on how distance is manifested in space and its role in event planning. Because no ideal space exists for political action, the dialogue between the people and those in power might take place anywhere. Thus, the key question is not only where a particular action occurs but also what types of opportunities does a particular place offer to communicate an ideology? How does setting influence the development of temporary relationships on a mass level? In exploring these questions, "Choosing a Place" provides a set of abstract, temporary categorizations for public spaces and offers a general overview of the dynamics between political events and places. Chapter 3 , "Enhancing the Impact," is about distance and distanciation and about the ability of activists to project their message beyond the event's geographical boundaries. More specifically, it examines the ways in which actors employ various spatial spheres and organizing principles to enhance their messages and claims. Tracking the ways in which actors operate reveals a sophisticated and multifaceted configuration of dissent, which extends beyond the boundaries of the nation-state and questions of national identity, thereby pressing us to abandon notions of resistance that assume that a subject stands vis-à-vis the established state's structure of power. Part I closes 
with chapter 4, "Bargaining Power," which discusses protests as bargaining processes regarding the appropriation of city spaces. Over the long history of civil protest, organizers have frequently struck bargains with authorities and police in advance. Negotiations between organizers, demonstrators, authorities, and police, both before and during the event, put limits on all parties and increase the predictability of encounters during demonstrations. The state's power to permit and limit citizens' tactics is still relevant today when addressing the relationships between activists and regimes, whether they are democratic or not.

Part II, "Spatial Choreographies," is about the specific spatial and temporal dimensions of protests. It investigates specific events' detailed designs, not only as aesthetic manifestations but also as tactics. Tactics, argues de Certeau in The Practice of Everyday Life (xix), depend on timing and opportunities that must be seized. However, tactics are not the "victories of the 'weak' over the 'strong' (whether the strength be that of the powerful people or the violence of things or of an imposed order, etc.)." Instead, they concern the clever implementation of the protest's planning strategy. Clearly, tactics cannot be exactly replicated (even by the same activists), but they can definitely inspire other protesters. The unfixed nature of a protest's design is its strength, allowing activists to contextualize their ideas and actions.

"Spatial Choreographies" addresses the dynamics between temporalities and their spatial attributes. They are microanalyses of events that focus on the dynamics between the body and physical settings, between the protest's social dynamics and ritual components (e.g., marching, gathering, and singing), dress code, and schedule (i.e., the timing and duration of the event). Chapter 5, "Staging the Action," provides an introduction to these features, presenting the dramaturgical attributes of three key spatial protest prototypes: the spectacle, the procession, and the place-making. Under each prototype, one can find extremely diverse spatial choreographies. In addition, although all protests are time-space specific and embedded in a concrete political, historical, and spatial context, some protests can also be viewed as offering a sociopolitical choreography in space that can be found, with alterations, in other contexts.

Chapters 6, 7, and 8 present examples of these spatial choreographies. Chapter 6, "Spectacles," analyzes events, whether large- or small-scale performances, that tend to be well-planned gatherings with particular sensitivity to the physical order or architectural attributes of a space. Chapter 7, "Processions," examines events in which walking or marching figure prominently, placing the protest in the mundane and economic space of the city. Chapter 8, "Place-Making," investigates events that use object(s) in a given setting as the heart of the event. The body in this type of action is secondary to the object, though they are closely linked. All the events analyzed in these chapters are major political actions and key events on a national or international scale from the 1960 s to the present day. However, these varied cases do not represent a comprehensive list, nor do they aspire to constitute a complete list. Instead, these events illustrate poignant examples of spatial choreographies. 
Methodologically, the analysis of the different sites follows the same key steps and includes the following: (1) archival research on the sites and events in question; (2) physical and architectural analyses of the sites; (3) interviews with key figures in the city (citizens or people from the institution, planners, and decision makers); and (4) interviews with the activists who were involved in the action. The interviews with the activists focused on planning the protest and the use of space and included generic questions about the organization of the protest, the planning process for the event, the use and choice of a particular tactic in a particular place at a particular time, the legality or illegality of the action, policing, and violence.

Part III, "Continuum," reflects on the power to perform protestability in our current times. In the closing chapter of the book, "Performing Protestability," it is suggested that protests do not emerge out of the blue as total surprises. Prior social and political dynamics nurture their emergence, and such dynamics include lowkey public actions to which the government or the public does not pay attention. This dynamic of creating and managing protests as social processes is on the rise because it is a very basic tool people can use to temporarily break free of individualist constraints, resist the powers that be, and suggest a collective counterposition. Regarding contemporary cities' politics, this chapter discusses activists' challenges in realizing change and in modifying practices of distance.

\section{ACKNOWLEDGMENTS}

Obviously, large research projects need significant support. I am extremely grateful for the generous support of several agencies that made this project possible: the US Fulbright Program, the Marie Curie International Outgoing Fellowships (IOF, FP6), and the Marie Curie International Reintegration Grants (IRG, FP7) of the Commission of the European Communities.

This project has a long history. As a Fulbright and Marie Curie postdoc fellow, I started the project at the Massachusetts Institute of Technology (MIT) in early 2005 and completed it when I returned to Tel Aviv as a faculty member and the head of the Contemporary Urban Design Laboratory. While at MIT, I had the good fortune to meet two professors, Larry Vale and Diane Davis, both of whom hosted and supported my stay and my work; our conversations on the relationships between space and politics significantly contributed to the development of this project. I am also thankful to Larry for his careful reading of the first draft of this book and his important and insightful comments. At MIT, I also met Tunney Lee, whose thoughts and wisdom helped me better understand the dynamics of the 1960 s in the United States. I would also like to thank Jim Burr, my editor at the University of Texas Press, and to Fernando Lara and an anonymous reviewer for their useful comments and advice. 